\title{
Rapid Feedback Responses Correlate with Reach Adaptation and Properties of Novel Upper Limb Loads
}

\author{
Tyler Cluff ${ }^{1}$ and Stephen H. Scott ${ }^{1,2,3}$ \\ ${ }^{1}$ Centre for Neuroscience Studies, ${ }^{2}$ Department of Biomedical and Molecular Sciences, and ${ }^{3}$ Department of Medicine, Queen's University, Kingston, Ontario \\ K7L 3N6, Canada
}

\begin{abstract}
A hallmark of voluntary motor control is the ability to adjust motor patterns for novel mechanical or visuomotor contexts. Recent work has also highlighted the importance of feedback for voluntary control, leading to the hypothesis that feedback responses should adapt when we learn new motor skills. We tested this prediction with a novel paradigm requiring that human subjects adapt to a viscous elbow load while reaching to three targets. Target 1 required combined shoulder and elbow motion, target 2 required only elbow motion, and target 3 (probe target) required shoulder but no elbow motion. This simple approach controlled muscle activity at the probe target before, during, and after the application of novel elbow loads. Our paradigm allowed us to perturb the elbow during reaching movements to the probe target and identify several key properties of adapted stretch responses. Adapted long-latency responses expressed (de-) adaptation similar to reaching errors observed when we introduced (removed) the elbow load. Moreover, reaching errors during learning correlated with changes in the long-latency response, showing subjects who adapted more to the elbow load displayed greater modulation of their stretch responses. These adapted responses were sensitive to the size and direction of the viscous training load. Our results highlight an important link between the adaptation of feedforward and feedback control and suggest a key part of motor adaptation is to adjust feedback responses to the requirements of novel motor skills.
\end{abstract}

\section{Introduction}

An important concept in motor neuroscience is that adaptation alters our motor commands to compensate for changes in the physics of our limb and environment (Wolpert et al., 2011). Recent theories have also emphasized the importance of feedback in voluntary control (Todorov and Jordan, 2002; Diedrichsen et al., 2010) and several studies have highlighted flexible, goal-directed feedback responses (Nashed et al., 2012; Selen et al., 2012). These findings imply an intimate relationship between feedback control and voluntary action and lead to the hypothesis that feedback responses should adapt when we learn new motor skills (Scott, 2012).

The adaptation of feedback responses has been examined using force-field learning tasks (Kobak and Mehring, 2012; Yousif and Diedrichsen, 2012). In an experiment by Wagner and Smith (2008), participants performed reaching movements in the presence of velocity-dependent hand forces, and on random trials,

Received Jan. 19, 2013; revised July 17, 2013; accepted Aug. 28, 2013.

Author contributions: T.C. and S.H.S. designed research; T.C. and S.H.S. performed research; T.C. and S.H.S. contributed unpublished reagents/analytic tools; T.C. and S.H.S. analyzed data; T.C. and S.H.S. wrote the paper.

This work was supported by the National Sciences and Engineering Research Council of Canada (NSERC). T.C. was supported by salary awards from the Ontario Ministry of Research and Innovation (MRI) and NSERC. S.H.S. was supported by a GSK-CIHR chair in Neuroscience. We thank Kim Moore and Justin Peterson for their expert technical support. We also thank Isaac Kurtzer, Andrew Pruszynski, and members of the LIMB Laboratory for helpful feedback on this paper.

S.H.S. is associated with BKIN Technologies, which commercializes the KINARM robotic device used in this study. Correspondence should be addressed to either of the following: Dr. Tyler Cluff, Laboratory of Integrative Motor Behaviour, Centre for Neuroscience Studies, 18 Stuart Street, Queen's University, Kingston, 0N, K7L 3N6, Canada; E-mail: tyler.cluff@queensu.ca; or Dr Stephen H. Scott, Laboratory of Integrative Motor Behaviour, Centre for Neuroscience Studies, 18 Stuart Street, Queen's University, Kingston, 0N, K7L 3N6, Canada. E-mail: steve.scott@queensu.ca.

DOI:10.1523/JNEUROSCI.0263-13.2013

Copyright $(2013$ the authors $\quad 0270-6474 / 13 / 3315903-12 \$ 15.00 / 0$ perturbations displaced their hand in a channel that prevented lateral motion. After adapting to the force field, subjects generated corrections appropriate for the novel dynamics, producing leftward forces within $200 \mathrm{~ms}$ of a perturbation that displaced the hand toward the target and rightward forces when the perturbation pushed the hand away from the target. These findings illustrate that feedback corrections take advantage of internal models engaged for voluntary behavior to follow the expected time course of novel forces. However, it is unclear whether these adapted corrections reflect voluntary EMG changes $(>100 \mathrm{~ms})$ or earlier changes in the stretch response $(<100 \mathrm{~ms})$.

Investigating feedback responses over rapid timescales $(<100$ $\mathrm{ms}$ ) is difficult because motor adaptation increases muscle activity during reaching (Shadmehr and Moussavi, 2000), and when the arm is unexpectedly bumped by a perturbation, any increases in background muscle activity will amplify short-latency (SL) and long-latency (LL) stretch responses (Matthews, 1986; Pruszynski et al., 2009). This "automatic gain-scaling" effect has made it difficult to isolate adapted stretch responses from automatic spinal processes engaged during the ongoing movement. As a result, changes in feedback responses during adaptation have only indirectly been measured in postural control before movement onset (Ahmadi-Pajouh et al., 2012) or by perturbing visual feedback (Franklin et al., 2012). A key challenge for exploring how motor adaptation influences feedback responses will be to develop techniques where the level of muscle activity is unaltered by the adaptation process.

Here we develop a paradigm that allows us to investigate the relationship between motor adaptation and muscle stretch responses. By maintaining constant elbow muscle activity during reaching movements to a target that only requires shoulder mo- 
A
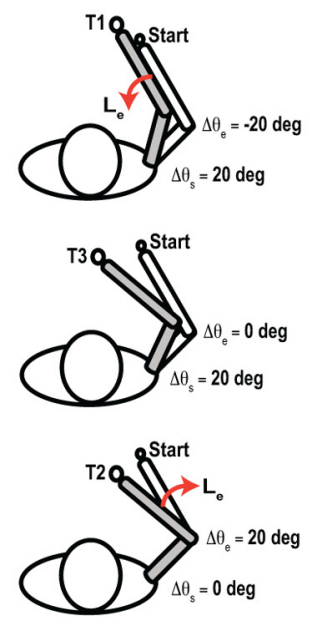

B

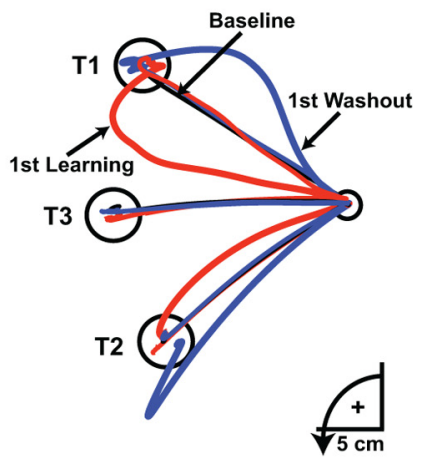

C
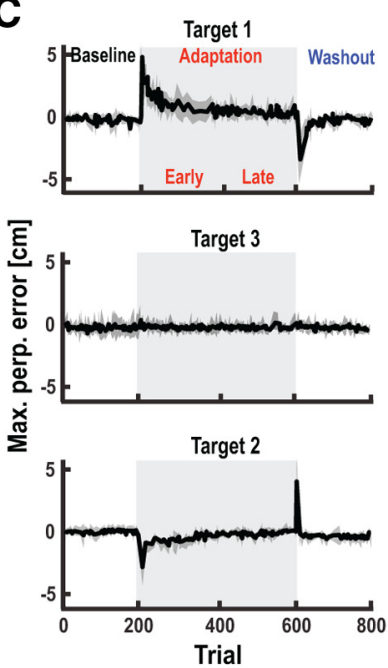

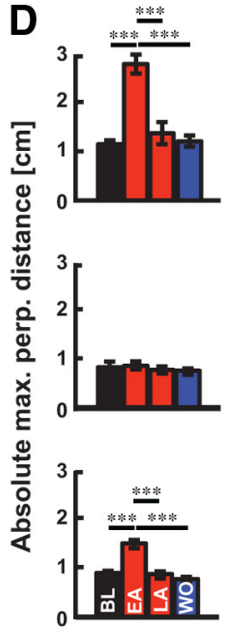

Adaptation phase

Figure 1. Experimental apparatus and learning patterns. $\boldsymbol{A}$, Experimental setup and target configuration. Red arrow denotes the viscous elbow load applied during reaching movements in the adaptation block. Subjects reached to targets configured in a joint-based coordinate system (T1-T3). B, Representative hand paths obtained from a single subject during training. Black, red, and blue traces correspond to baseline, adaptation, and washout phases. Thick lines are the first trial, thin lines the last trial in each respective block. C, Trial-by-trial changes in maximum perpendicular error at each target (mean \pm SEM). Positive values denote counterclockwise rotation of the hand from the target (elbow flexion is positive). Light shaded region corresponds to the adaptation period when the novel elbow load was applied. $\boldsymbol{D}$, Reaching errors observed at each target (mean \pm SEM). Black, red, and blue bars correspond to the mean of the maximum perpendicular errors in the baseline (BL), early adaptation (EA), late adaptation (LA), and washout (W0) phases, respectively. ${ }^{*} p<0.05,{ }^{* *} p<0.01,{ }^{* * *} p<0.001$.

tion (i.e., probe target) we dissociated adapted feedback responses from altered muscle stiffness or coactivation, and measured the time course of feedback adaptation. We found subjects that adapted more to the load showed greater modulation of their stretch responses, highlighting an important relationship between feedback responses and performance in the adapted motor skill. Moreover, these adapted stretch responses were sensitive to the size and direction of the viscous training load. Our results emphasize that LL responses contribute to flexible control strategies during motor skill acquisition.

\section{Materials and Methods}

Subjects. A total of 60 healthy subjects (19-47 years of age, 31 females) participated in one of four experiments $(\sim 2 \mathrm{~h})$. The subjects were righthanded, had normal or corrected vision, and reported no neurological or musculoskeletal disorders. The Queen's University Research Ethics Committee approved the procedures, and subjects provided written informed consent. The subjects were compensated for their time and could withdraw from the study at any time without penalty.

Apparatus and behavioral task. Subjects performed a target-directed reaching task with their right arm supported in a robotic exoskeleton device (KINARM, BKIN Technologies). The robotic device permits upper limb motion in the horizontal plane and can apply independent mechanical loads to the shoulder and elbow joints (Scott, 1999; Singh and Scott, 2003). Visual targets and hand-aligned feedback were projected into the plane of the subject's hand via a semisilvered mirror. We blocked direct vision of the upper limb using a physical barrier and cloth bib.

The behavioral task is illustrated in Figure $1 A$. At the beginning of each trial, the visual display consisted of a $1 \mathrm{~cm}$ diameter start position that maintained the same shoulder and elbow angles across subjects. The shoulder angle was $35^{\circ}$ relative to the frontal plane and the elbow angle was $75^{\circ}$, defined as the external angle of the forearm relative to the upper $\operatorname{arm}\left(0^{\circ}\right.$ is full extension). To begin the trial, subjects moved their hand (displayed as a $0.8-\mathrm{cm}$-diameter white cursor) to the start position. After a brief delay (1000 $\pm 500 \mathrm{~ms}$, uniformly distributed), we randomly presented one of three targets (displayed as $1.2-\mathrm{cm}$-diameter red circles) configured in joint-based coordinates (Fig. 1A, T1-T3). Target 1 (T1) required combined shoulder and elbow motion $\left(20^{\circ}\right.$ shoulder flexion, $20^{\circ}$ elbow extension), $\mathrm{T} 2$ required only elbow motion $\left(20^{\circ}\right.$ elbow flex- ion), and $\mathrm{T} 3$ required only shoulder motion ( $20^{\circ}$ shoulder flexion). The subjects were required to reach the targets within $400-750 \mathrm{~ms}$ of movement onset. The end target turned green to indicate successful performance but turned blue (too fast) or red (too slow) if the time constraints were not satisfied. At the start of each trial, we applied a $1 \mathrm{Nm}$ extensor background load to enhance elbow flexor stretch responses (500 ms sigmoidal ramp-to-constant profile). At the end of each trial, the background load ramped down (500 ms sigmoidal ramp-to-constant profile) and remained off for a $2 \mathrm{~s}$ intertrial period.

At the end of each experiment, the subjects performed a postural task requiring them to stabilize their hand within a central target (displayed as a $1 \mathrm{~cm}$ radius red circle) while resisting against a background load. The postural target was located at the same arm configuration as the start position in the main experiment (shoulder angle $=35^{\circ}$, elbow angle $=$ $75^{\circ}$ ). To begin the trial, subjects moved their hand (displayed as a $0.8 \mathrm{~cm}$ diameter white cursor) to the central target. After a brief delay, we randomly presented background loads ( $250 \mathrm{~ms}$ sigmoidal ramp-to-constant profile) to excite the shoulder and elbow flexors $(-1 \mathrm{Nm})$ or extensors $(+1 \mathrm{Nm})$. After holding the target position for $15 \mathrm{~s}$, the background load ramped down slowly and remained off for a $2 \mathrm{~s}$ intertrial period $(250 \mathrm{~ms}$ sigmoidal ramp-to-constant profile). Ten repetitions were performed per background load. We processed the data by removing the first $3 \mathrm{~s}$ of muscle data to avoid EMG changes when the background load was introduced. We then calculated the average of the full-wave rectified EMG over the remaining $12 \mathrm{~s}$ of the stabilization period for trials exciting each muscle. We averaged these constants across repetitions and normalized each muscle's full-wave rectified EMG during the main experiments to their respective normalization constant. Thus, 1 arbitrary EMG unit (a.u.) in each experiment is the level of muscle activity needed to stabilize against a $1 \mathrm{Nm}$ background load.

Experiment 1. We applied novel elbow-joint loads to investigate the adaptation of muscle stretch responses (Fig. 1). Subjects $(n=10)$ first performed unloaded reaching movements to determine the sensitivity of their muscle stretch responses. We then applied a viscous elbow joint load (i.e., resistive):

$$
\left[\begin{array}{l}
L_{s} \\
L_{e}
\end{array}\right]=\left[\begin{array}{cc}
0 & 0 \\
0 & -1.5
\end{array}\right]\left[\begin{array}{c}
\dot{\theta}_{s} \\
\dot{\theta}_{e}
\end{array}\right],
$$

where $\left[\mathrm{L}_{s} \mathrm{~L}_{e}\right]^{\mathrm{T}}$ were the velocity-dependent torques $(\mathrm{Nm})$ applied by the robotic device, and $\dot{\theta}_{s}$ and $\dot{\theta}_{e}$ were the angular shoulder and elbow veloc- 
ities ( $\mathrm{rad} / \mathrm{s})$. After training with the viscous elbow load, subjects performed unloaded trials to investigate the de-adaptation of reaching movements. The experiment was divided into eight blocks of 100 trials ( $\sim 10 \mathrm{~min} /$ block) separated into four phases: baseline (two blocks), early adaptation (two blocks), late adaptation (two blocks), and washout (two blocks). We provided $60 \mathrm{~s}$ rest breaks between trial blocks and additional rest breaks when requested.

On selected trials, we probed feedback responses with a $2 \mathrm{Nm}$ step torque perturbation (10 $\mathrm{ms}$ sigmoidal ramp-to-constant profile) that stretched the elbow flexors during the ongoing reach. The perturbation was applied at movement onset, which we determined using a hand velocity criterion of $0.5 \mathrm{~cm} / \mathrm{s}$. Hand feedback was extinguished at perturbation onset to ensure that feedback responses were guided by limb afferent feedback. The same time constraints and performance feedback were used as in the unperturbed reaching trials. We characterized the adaptation of stretch responses by randomizing the order of unperturbed trials to the three targets, and on every eighth trial, applied mechanical perturbations on movements to the probe target (T3; probability of perturbation $=0.25$ ). Applying the perturbations in a fixed order allowed us to investigate the link between reach adaptation and altered feedback responses by measuring feedback responses regularly throughout the adaptation period.

Control experiment: random versus blocked perturbation trials. We performed a control experiment to confirm that background EMG and stretch responses were similar when perturbed and unperturbed reaching trials were presented in random or pseudorandom order (i.e., the order of perturbations was fixed). After a block of unloaded reaching trials (150 trials), we applied the same viscous elbow load as in Experiment 1 for 600 trials $(-1.5 \mathrm{Nm} \cdot \mathrm{s} / \mathrm{rad})$. We started probing feedback responses after the first block of adaptation trials (200 trials) using the same $2 \mathrm{Nm}$ step torque perturbation to stretch the elbow flexor muscles during the reach (10 ms sigmoidal ramp-to-constant profile). In the pseudorandom trial block ( 200 trials; 25 perturbations), we randomized the order of unperturbed trials to the three targets, and on every eighth trial applied mechanical perturbations at the onset of reaching movements directed to the probe target $(\mathrm{T} 3$; probability of perturbation $=$ 0.25 ). In contrast, we interleaved perturbed and unperturbed trials during the random block while maintaining the same number of probe trials (T3; probability of perturbation $=0.25)$. One group of subjects $(n=5)$ performed the pseudorandom block followed by the random block, whereas the other group $(n=5)$ first performed the randomized block of trials. After verifying there were no differences in responses between groups, we pooled the data to contrast feedback responses and perturbation-evoked elbow motion between conditions.

Experiment 2. A number of motor adaptation studies have demonstrated that reach-related muscle activity scales with the physical requirements of the task, including changes in the inertia of the arm or the introduction of viscous force fields (Hoffman and Strick, 1993; Gottlieb et al., 1995; Pfann et al., 1998). Motivated by these studies, we performed an experiment to test whether the size of the viscous elbow load would modulate muscle stretch responses. Our prediction is that training with a larger viscous load will increase the amplitude of LL stretch responses.

We tested our prediction using the same target configuration as in Experiment 1 . One group of subjects $(n=10)$ trained with a $1 \mathrm{Nm} \cdot \mathrm{s} / \mathrm{rad}$ followed by $2 \mathrm{Nm} \cdot \mathrm{s} / \mathrm{rad}$ viscous elbow load, whereas the other group $(n=10)$ trained with the $2 \mathrm{Nm} \cdot \mathrm{s} / \mathrm{rad}$ followed by the $1 \mathrm{Nm} \cdot \mathrm{s} / \mathrm{rad}$ elbow load. After a block of unloaded reaching trials (160 trials), we applied a viscous elbow load that required additional muscle activity to reach the training targets (see Fig. 5A, T1,T2). Reaching movements to the probe target required only shoulder motion and did not produce adaptation (T3). After subjects trained with the viscous elbow load (240 trials), we modified the relationship between muscle force and elbow motion by changing the velocity-dependent elbow load (240 trials). All other aspects of the experiment were identical to Experiment 1 including the amplitude ( $2 \mathrm{Nm}, 10 \mathrm{~ms}$ ramp-to-constant profile) and fixed order of perturbation trials (every eighth reaching trial; probability of perturbation at T3 $=0.25$ ), electrode placement, EMG recording and analysis, and the kinematic analysis of feedback corrections.
Experiment 3. Training with novel mechanical loads produces adaptation in muscles that counter these loads (Shadmehr and Moussavi, 2000; Malfait et al., 2005; Mattar and Ostry, 2007). We performed an additional experiment to test whether adapted feedback responses would be sensitive to the direction of the training load. Our prediction is that a viscous load that resists elbow flexion motion will produce adapted stretch responses in the brachioradialis muscle but will not alter triceps stretch responses.

We tested our prediction using Targets 2 and 3 from Experiment 1. After a block of unloaded reaching trials ( 160 trials), we applied a viscous elbow load (480 trials) that extended the elbow during reaching movements to Target 2 and required additional brachioradialis activity to produce straight movements (see Fig. 6A, T2). Reaching to Target 3 did not require elbow motion, and thus, there was no adaptation required to successfully reach the target (probe target). On random trials, we probed feedback responses using a $2 \mathrm{Nm}$ step torque perturbation $(10 \mathrm{~ms}$ sigmoidal ramp-to-constant profile) that stretched either the elbow flexor or extensor muscles during the reach. One group of subjects $(n=10)$ performed the task with the elbow flexors preloaded with a constant 1 $\mathrm{Nm}$ extensor load, whereas a second group of subjects $(n=10)$ performed the task with the elbow extensors preloaded with a constant $1 \mathrm{Nm}$ flexor load. All other aspects of the task including electrode placement, EMG recording and analysis, and the kinematic analysis of feedback corrections were identical to Experiment 1.

\section{Data analysis}

\section{Kinematic recordings and analysis}

Shoulder and elbow angles were sampled at $1 \mathrm{kHz}$ and digitally low-pass filtered (second-order, dual-pass Butterworth, $30 \mathrm{~Hz}$ effective cutoff). We quantified the adaptation of reaching movements using perpendicular hand-path errors relative to a straight line joining the start position and target. As shown in Figure 1B, positive hand-path errors correspond to counterclockwise rotation of the hand path from the target (elbow flexion is positive). Our adaptation metric was the peak perpendicular hand error during unperturbed reaching trials. Differences in reaching trajectories were quantified using the average hand-path errors during baseline reaching, the first 25 trials of the adaptation block (i.e., early adaptation), the last 25 trials of the adaptation block (i.e., late adaptation), and the last 25 trials of the washout block.

\section{EMG recordings and analysis}

The activity of the proximal upper limb muscles was recorded using bipolar surface electrodes (DE 2.1 Single Differential Electrode, Delsys). We recorded brachioradialis (elbow flexor), triceps lateral (elbow extensor), pectoralis major (shoulder flexor), and posterior deltoid EMG (shoulder extensor). Before electrode placement, we cleaned the skin with alcohol and an abrasive gel to improve signal conductance. Electrode were positioned to maximize the signal for individual muscles and to minimize crosstalk between muscles. A ground electrode was placed over the lateral malleolus of the ankle. The EMG signals were amplified (gain $=10^{3}-10^{4}$ ) and sampled at $1 \mathrm{kHz}$ using a Delsys Bagnoli system. The EMG data were aligned to perturbation onset (i.e., reach onset), bandpass filtered between 20 and $450 \mathrm{~Hz}$ (third-order, dual-pass Butterworth), full-wave rectified, and normalized before analysis. We quantified the adaptation of feedforward control using the average muscle activation for $300 \mathrm{~ms}$ before the onset (hand velocity $>0.5 \mathrm{~cm} / \mathrm{s}$ ) of unperturbed reaching movements. A final measure used to quantify adaptation was the integrated EMG of the antagonist pair of shoulder (posterior deltoid, pectoralis major) and elbow (triceps lateral, brachioradialis) muscles during the $300 \mathrm{~ms}$ period before reach onset. We calculated this measure for individual trials on a subject-bysubject basis.

Muscle stretch responses were quantified by aligning EMG data to reach onset (i.e., perturbation onset) and subtracting EMG in unperturbed trials from perturbed trials $(\Delta \mathrm{EMG})$. We calculated the mean $\triangle \mathrm{EMG}$ in the time windows $-50-0 \mathrm{~ms}$ (pre-perturbation activity; PRE), 20-45 ms (SL), 45-105 ms (LL), and 105-200 ms (early voluntary response; VOL). Individual subject's stretch responses were averaged over trials in the baseline, late adaptation (last 25 perturbations in the adap- 
A
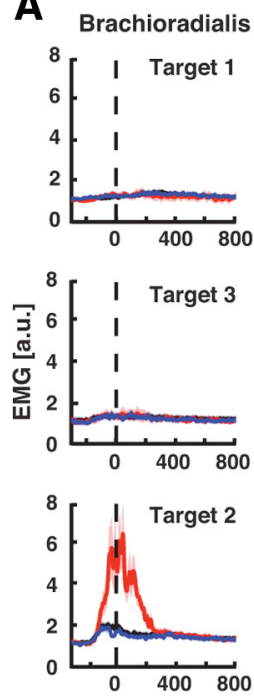

Triceps Lateral
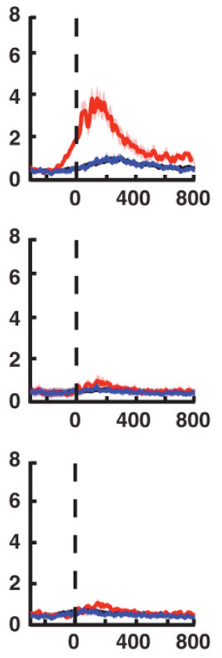

Pectoralis Major
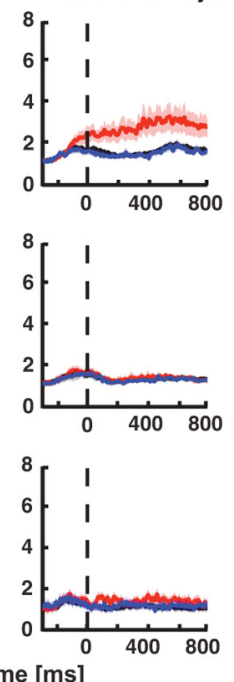

Posterior Deltoid
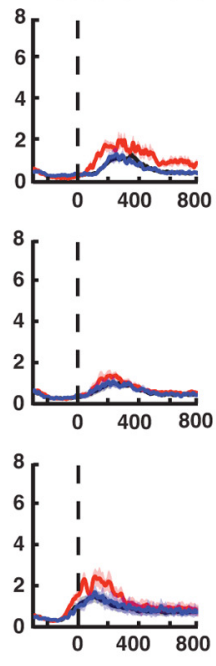

B
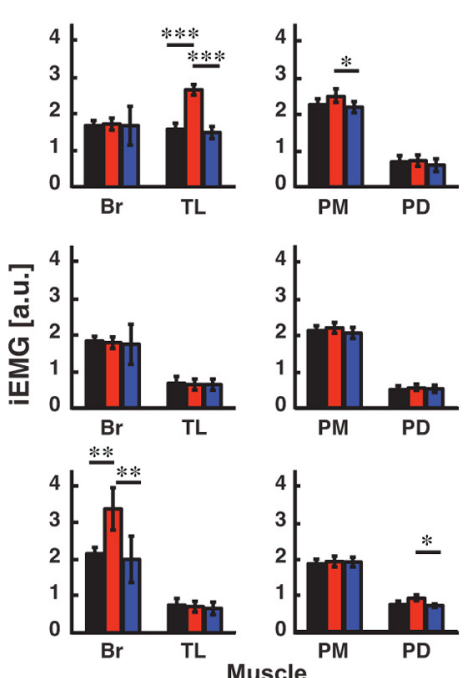

Figure 2. Muscle activity and integrated EMG. A, EMG activity of four monoarticular arm muscles is shown for each reaching target during the baseline (black trace), adaptation (red trace), and washout phases (blue trace). Horizontal axis is the time relative to reach onset (dashed vertical line) and the vertical axis is normalized muscle activity (a.u.). Due to the normalization process, 1 a.u. corresponds to the level of muscle activity needed to stabilize against a $1 \mathrm{Nm}$ constant load. EMG data are aligned to movement onset (0 ms) and the shaded region indicates the SEM. For display purposes, the EMG was smoothed using a 10 sample $(10 \mathrm{~ms})$ moving-average. $\boldsymbol{B}$, Integrated EMG activity for the pair of antagonist muscles spanning the elbow and shoulder joints at each target. All values were obtained from the 300 ms window before movement onset. ${ }^{*} p<0.05,{ }^{* *} p<0.01,{ }^{* * *} p<0.001$.

tation phase), and washout phases. We quantified the simultaneous activity of the antagonist pair of elbow (triceps lateral, brachioradialis) and shoulder (posterior deltoid, pectoralis major) muscles in each phase of the stretch response, i.e., muscle coactivation. Muscle coactivation can help counter unexpected perturbations and can be flexibly modified to counter environmental instabilities and motor noise (Loeb et al., 1999; Brown and Loeb, 2000; Burdet et al., 2001; Franklin et al., 2007; Selen et al., 2009).

$$
\text { Co-contraction ratio }=\left(\frac{\text { Evoked Activity }_{\text {TriLat } / \text { PostDelt }}}{\text { Evoked Activity }}\right) .
$$

Positive values near 1 indicate a similar amount of activity in antagonist muscle pairs, i.e., high cocontraction, whereas small values near 0 indicate small coactivation at each joint. Note these ratios were calculated for individual subjects from normalized muscle activity in each phase of the experiment.

Statistical analysis. Two-way ANOVAs with repeated-measures were used to compare hand-path errors and muscle activity across targets and phases of adaptation. Separate one-way ANOVAs with repeatedmeasures were used to examine the adaptation of feedback corrections at the test target. Two-way ANOVAs were used to investigate changes in stretch responses in the PRE, SL, LL, and VOL time periods in addition to the level of muscle coactivation in each of these time windows. Finally, we performed linear regression analysis to quantify the relationship between adapted reaching movements (i.e., feedforward control) and changes in LL responses (i.e., feedback control). The statistical analysis was performed in MATLAB (r2010a, Mathworks) and the threshold significance level was set to 0.05 . Post hoc comparisons were performed using paired $t$ tests (single-sided) with Holm-Bonferonni corrections (Holm, 1979).

\section{Results}

\section{Adaptation of reaching movements}

Figure $1 A$ shows a typical subject's reaching behavior. For this example, we have shown averaged hand trajectories during baseline reaching (black trace), as well as the first and last trials of the adaptation (red trace) and washout phases (blue trace). The viscous elbow load caused curved reaching trajectories to the training targets, producing elbow flexion at target 1 and elbow extension at Target 2 . Subjects quickly adapted to the elbow load, and within 50 trials, reaching errors approached baseline performance at both training targets (Fig. $1 B, C$ ). We performed a twoway repeated-measure ANOVA comparing reaching errors between targets (T1-T3) and phases of the experiment (baseline, early adaptation, late adaptation, washout). There was a significant target by learning phase interaction $\left(F_{(4,36)}=8.23, p<\right.$ $0.001)$. The elbow load produced reaching errors at both training targets (Fig. $1 B-D$; paired $t$ test, baseline vs early adaptation, both $p<0.001$ ), which by the end of adaptation were indistinguishable from unloaded movements (baseline vs late adaptation, both $p>0.05)$.

A two-way repeated-measure ANOVA was also performed on muscle activity during the $300 \mathrm{~ms}$ period before movement onset (adaptation phase $\times$ target interaction; $F_{(4,36)}=8.07, p<0.001$ ). At target 1 , training increased triceps activity (Fig. $2 A, B$; late adaptation vs baseline, $p<0.001$; late adaptation vs washout, $p<$ 0.001 ), and increased brachioradialis activity at Target 2 (Fig. $2 A, B$; late adaptation vs $p<0.01)$. Learning also produced an increase in posterior deltoid activity at Target 2 (late adaptation vs baseline, $p<0.01$; late adaptation vs washout, $p<0.01$ ). In agreement with studies examining adaptation to novel dynamics (Thoroughman and Shadmehr, 1999; Milner and Franklin, 2005; Darainy and Ostry, 2008; Franklin et al., 2008) we observed muscle coactivation between the pectoralis major and posterior deltoid muscles at the end of reaching movements to Target 1 , but not before movement onset (Fig. 2A,B; cf.Thoroughman and Shadmehr, 1999). Moreover, we found mirror-trajectory errors when we removed the load at the training targets (Fig. $1 B-D, \mathrm{~T} 1$ and T2; baseline vs last 25 trials in the washout phase, both $p<$ $0.01)$. These after-effect deviations suggest that subjects actively increased their muscle activity for the expected time course of the elbow-joint load.

Importantly, we found reaching movements to the probe target were not significantly altered when we introduced the viscous elbow load, nor were they altered during late adaptation or washout (Fig. $1 B, C ; F_{(2,18)}<1.20$, all $p>0.05$ ). This lack of reach 
A

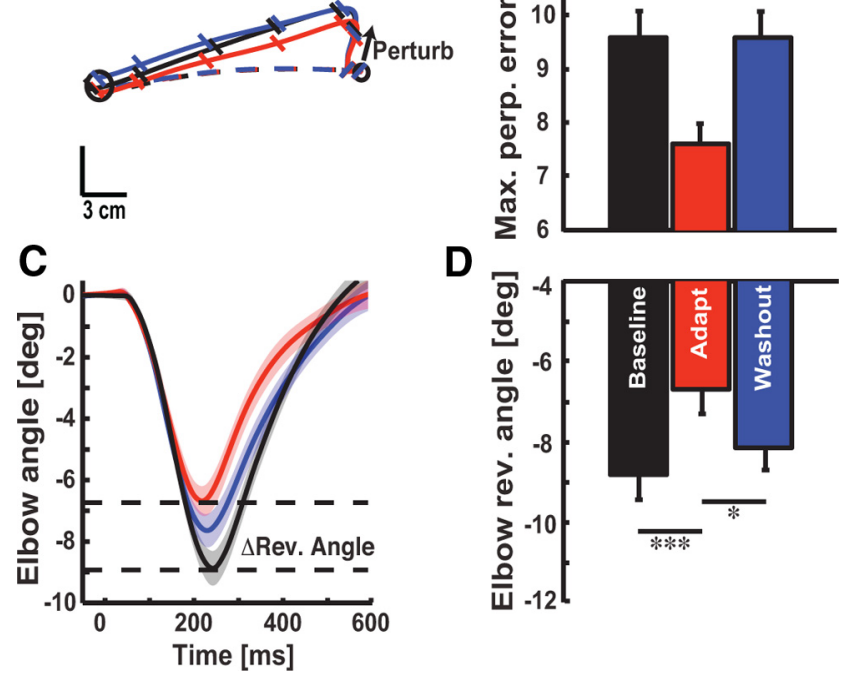

Figure 3. Comparison of kinematic responses evoked by mechanical perturbations. $A$, Exemplar data from a single subject showing corrective responses elicited by a mechanical perturbation. Black, red, and blue traces correspond to average responses obtained during the baseline, late adaptation, and washout phases. Dashed lines are the average from unperturbed reaching movements in each phase of the experiment; solid lines are the average from perturbation trials. Diagonal tick marks are the hand position every $100 \mathrm{~ms}$. B, Perturbation-evoked hand motion (mean \pm SEM). Data are plotted in the same format as in $\boldsymbol{A}$. C, Temporal kinematics of the elbow joint. Data aligned to perturbation onset $(t=0 \mathrm{~ms}$; mean $\pm S E M)$. $D$, Same format as $\boldsymbol{B}$, but for elbow reversal angles. ${ }^{*} p<0.05,{ }^{* *} p<0.01,{ }^{* * *} p<0.001$.

adaptation was not associated with any significant changes in muscle activity at the probe target (Fig. $2 A, B ; F_{(2,18)}=1.05, p>$ $0.05)$, which establishes the upper limb muscles were at similar states when we applied perturbations in the baseline, adaptation, and washout blocks. In short, our paradigm led to adapted muscle activity at two training targets, but did not substantially alter reaching movements performed to the probe target. This key feature allowed us to attribute any changes in feedback responses to motor adaptation.

\section{Changes in rapid feedback corrections during the ongoing reach}

We assessed feedback responses by applying a perturbation that extended the elbow at the onset of reaching movements to the probe target. Figure $3 A$ presents a typical subject's averaged data showing that identical perturbations produced less hand motion in the adapted state. We found that perturbation-evoked hand motion (Fig. $3 B ; F_{(2,18)}=7.28, p<0.01$ ) and elbow joint motion (Fig. 3C; $F_{(2,18)}=11.51, p<0.001$ ) were clearly reduced in the adapted state (Fig. $3 B, D$; late adaptation vs baseline and washout, all $p<0.01)$. These adapted feedback corrections returned rapidly to baseline levels when the viscous load was removed after training (Fig. 3B, D; baseline vs washout, $p>0.05$ ), providing the first indication that rapid feedback corrections are modified by training with the viscous elbow load.

We recorded the EMG of elbow muscles in response to these rapid elbow perturbations. Figure 4 summarizes stretch responses elicited by the elbow-joint perturbation. In Figure 4, we plotted the across-subject average EMG $( \pm$ SEM) of the elbow (Fig. 4A) and shoulder muscles (Fig. 4B) obtained by subtracting each subject's perturbation responses from activity recorded during unperturbed trials $(\Delta \mathrm{EMG})$. The stretch responses show a classic short-latency component with little modulation over the first $45 \mathrm{~ms}$ (Fig. $4 A, \mathrm{SL}$ ). In contrast, brachioradialis responses (Fig. $4 A$, left) became larger $\sim 65 \mathrm{~ms}$ after the onset of the perturbation. Similar results were observed for the pectoralis major muscle presumably to compensate for the intersegmental dynamics expected under the internal model of limb motion (Soechting and Lacquaniti, 1988; Kurtzer et al., 2008, 2009; Pruszynski et al., 2011). Both triceps lateral and posterior deltoid exhibited an increase in inhibition in the late adaptation phase beginning in the LL time period (triceps lateral, $p<0.05$ ) and extending to the early voluntary response (VOL: triceps lateral, $p<0.05$; posterior deltoid: $p<0.05$ ).

Another notable feature was the low level of coactivation observed between the antagonist elbow (brachioradialis, triceps lateral) and shoulder (pectoralis major, posterior deltoid) muscles following mechanical perturbations that rapidly extended the elbow joint (Fig. 4C,D). We found that coactivation of the elbow flexors and extensors was reduced during the LL (baseline vs late adaptation, $p<0.05$; washout vs late adaptation, $p<0.05)$ and early voluntary responses (washout vs late adaptation, $p<0.05$ ) due to a combined upregulation of brachioradialis responses and corresponding inhibition of triceps lateral. We found a similar reduction in shoulder muscle coactivation in the voluntary time window (baseline vs adaptation, $p<0.05$; washout vs adaptation, $p<0.05)$.

Figure 5 summarizes changes in brachioradialis stretch responses across the learning paradigm. We found no indication that background muscle activity (Fig. $5 A ; F_{(2,18)}=1.80, p>0.05$ ) or early bursts of phasic activity in the SL response were influenced by adaptation $\left(F_{(2,18)}=1.05, p>0.05\right)$. These results are not surprising, as our paradigm controlled pre-perturbation activity at the probe target (T3), and for a given level of background muscle activity, the SL response has not been shown to modulate on the short time scales used in our experiment (Wolpaw, 1985). In contrast, adapted stretch responses achieved significance in the LL (Fig. $4 A$ and $B, F_{(2,18)}=8.73, p<0.01$ ) and VOL time periods $\left(F_{(2,18)}=6.97, p<0.001\right)$. Robust increases were observed in both the adapted LL (paired $t$ test: adaptation vs baseline and washout, $p$ 's $<0.01$ ) and VOL responses ( $p$ 's $<0.01)$. By the end of the washout phase, stretch responses were not significantly different from baseline levels (paired $t$ test: baseline vs washout, $p$ 's $>0.05)$. The results in Figure $5 A$ demonstrate that training with the elbow load produced adapted LL responses.

Although we have shown that feedback responses are upregulated during late adaptation, it is still unclear whether these stretch responses are linked to changes in voluntary behavior during adaptation. We examined the evolving amplitude of LL responses across probe trials to relate adapted reaching behavior to changes in feedback control. Figure $5 B$ demonstrates that LL responses show a qualitative correspondence with feedforward adaptation (Fig. 1C). Importantly, the amplitude of LL responses at the probe target increased during initial reaching trials with the elbow load, just as hand-path errors decreased at the training targets during reach adaptation (Fig. 1C). Moreover, the decrease in LL amplitude coincided with the de-adaptation of reaching behavior when the elbow load was removed after training. Collectively, our results suggest an important link between feedforward and feedback adaptation.

We further analyzed this link by examining the correlation between reaching performance and the amplitude of the LL response. We found that reaching errors averaged across training targets (T1 and T2) correlated negatively with changes in LL responses at the probe target (Fig. $5 C ; r(18)=-0.82, p<0.01$ ). 
This compelling finding demonstrates that subjects that adapted more to the elbow load (i.e., reduced error) also displayed larger increases in feedback responses at the probe target. Note it is unlikely that adaptation was caused by increased joint stiffness or changes in limb afferent feedback during the mechanical probe trials because there were no changes in muscle activity before perturbation onset, nor did we observe significant modulation of muscle coactivation during the feedback response. Finally, early elbow motion was similar in the baseline, adapted and deadapted states (Fig. 3C).

\section{Control experiment: LL responses are not affected by the order of perturbation trials}

We performed a control experiment to verify the altered stretch responses observed in Experiment 1 are due to adapted feedback processes and not an anticipatory voluntary response in preparation for the perturbation (Manning et al., 2012). We tested this hypothesis by having two groups of subjects train with the viscous elbow load used in Experiment 1. After the asymptote of learning (200 trials) we introduced perturbation trials that were presented either in a random or predictable order (the two groups performed these blocks in reverse order; Fig. 6A). The purpose of this control experiment is to rule out the possibility that subjects modify or bias their feedback responses to minimize hand displacement caused by the perturbation, enabling them to return more quickly to the target when the viscous load is present. This control experiment is crucial in our ability to track the adaptation of feedback responses because it allows us to directly measure differences in feedback responses that might suggest subjects anticipate the mechanical perturbation trials.

We did not find any evidence that perturbation-induced elbow motion was significantly altered between the two conditions (Fig. $6 B, C ; p=0.949$ ). We additionally examined muscle stretch responses to verify that subjects did not modify their responses when the perturbation trials were interleaved in a fixed order with unperturbed reaching movements (Fig. $6 D, E$ ). Similar to the kinematic data, we did not find evidence that background muscle activity (PRE, $p=0.971$ ), or muscle stretch responses in the SL $(p=0.996), \mathrm{LL}(p=0.757)$ or VOL response epochs $(p=0.984)$ were significantly altered between these two conditions. We therefore consider our results as a direct probe into feedback processes. Our claim is further supported by the observation that adapted stretch responses emerge much earlier $(\sim 65 \mathrm{~ms})$ than the reaction time latencies noted for rapid voluntary responses ( $>85 \mathrm{~ms}$; Manning et al., 2012), making us confident that our perturbations probe fast adaptive feedback processes. In summary, the lack of difference in background muscle activity and SL responses in Experiment 1 (Fig. 4) and the similarity between feedback responses (in all response epochs) observed in this control experiment suggest that perturbations presented in predictable order provide a reasonable probe into feedback control processes.
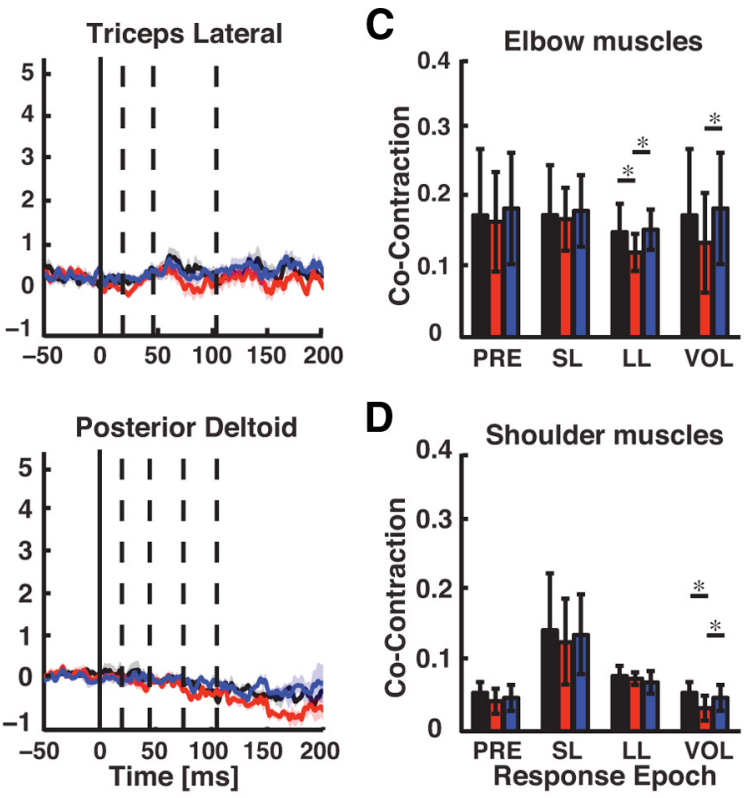

Figure 4. Muscle stretch responses across the adaptation paradigm. $\boldsymbol{A}$, Perturbation responses of the brachioradialis (left) and 列 Color scheme is the same as in $\boldsymbol{A}$ and $\boldsymbol{B}$. D, Coactivation ratio between pectoralis major and posterior deltoid stretch responses. Color

Adapted feedback responses reflect the physical requirements of the task

The results of Experiment 1 suggest that the motor system responds more vigorously to an identical perturbation that extends the elbow after training with a viscous elbow load. Given that reach-related muscle activity scales with the size of external loads applied to the upper limb (Hoffman and Strick, 1993), our second experiment tested whether feedback responses also scale with the size of the load experienced during training.

Figure $7 \mathrm{~A}$ presents a typical subject's averaged data showing that identical perturbations produced less hand motion when subjects trained with larger elbow loads. We found that perturbation-evoked hand motion depended on the viscosity of the elbow training load (Fig. $7 B ; F_{(2,38)}=10.89, p<0.001$ ), with perturbation-evoked hand motion decreasing with larger viscous load strengths $(2 \mathrm{Nm} \cdot \mathrm{s}<1 \mathrm{Nm} \cdot \mathrm{s}<$ unloaded, all $p<0.05)$. As in Experiment 1, there were no changes in elbow muscle activity associated with reaching movements to the probe $\operatorname{target}\left(F_{(2,38)}=\right.$ $1.14, p>0.05)$.

We recorded the EMG of the elbow muscles in response to identical step-torque perturbations in each condition (Fig. $7 D, E)$. We found that PRE activity $\left(F_{(2,38)}=1.20, p=0.427\right)$ and the SL spinal response were not significantly altered by elbow viscosity $\left(F_{(2,38)}=0.57, p=0.346\right)$. In contrast, stretch responses in the LL $\left(F_{(2,38)}=5.54, p<0.01\right)$ and VOL time periods $\left(F_{(2,38)}=5.49, p<0.01\right)$ were significantly modulated by elbow viscosity. We observed upregulation of stretch responses in the LL and VOL time periods that increased with the strength of the viscous elbow load (Fig. $7 E ; 2 \mathrm{Nm} \cdot \mathrm{s} / \mathrm{rad}>$ $1 \mathrm{Nm} \cdot \mathrm{s} / \mathrm{rad}>$ unloaded, all $p<0.05$ ). These findings establish that LL responses scale with the size of the load experienced during training. 
A

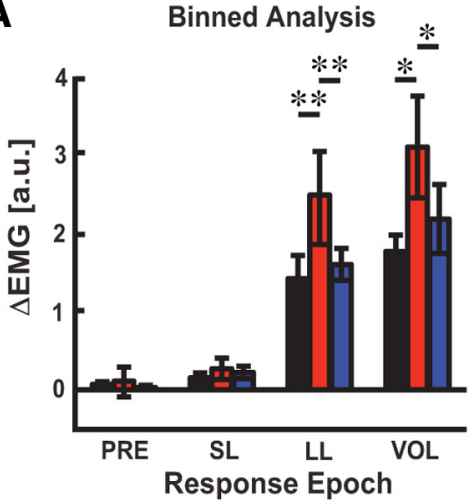

B
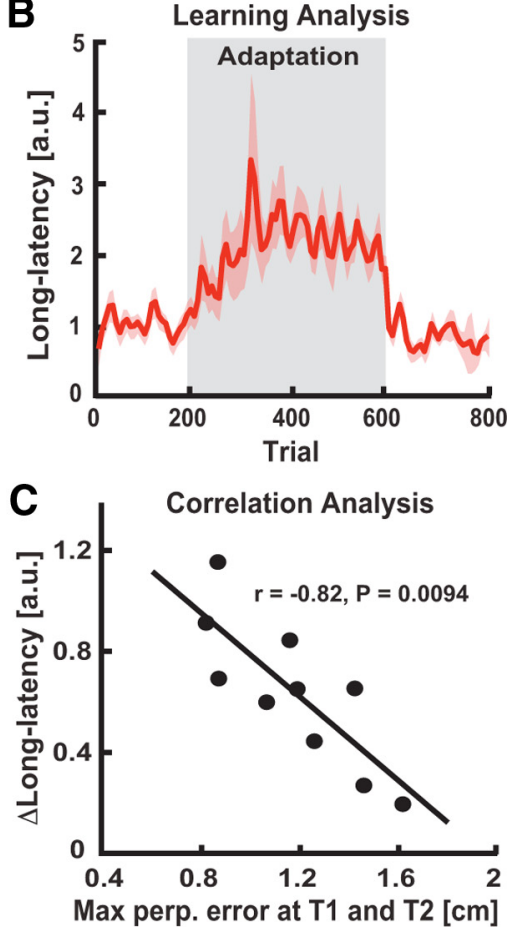

Figure 5. Magnitude of brachioradialis stretch responses and relation to adaptation of voluntary reaching behavior. $\boldsymbol{A}$, Binned analysis of brachioradialis stretch responses (mean \pm SEM). Black, red, and blue bars correspond to brachioradialis stretch responses in the baseline, late adaptation, and washout phases. $\boldsymbol{B}$, Trial-by-trial adaptation of muscle activity in the longlatency time period (mean \pm SEM). $\boldsymbol{C}$, Correlates of reach adaptation in feedback responses. Vertical axis is change in LL responses between baseline and late adaptation phase. Horizontal axis shows individual subjects' perpendicular errors averaged across the training targets (T1 and T2) for the late adaptation phase. ${ }^{*} p<0.05,{ }^{* *} p<0.01,{ }^{* *} p<0.001$.

Adapted feedback responses are sensitive to the direction of the load encountered in training

We performed a third experiment to investigate whether adapted muscle stretch responses were sensitive to the direction of the viscous elbow load encountered during training. The subjects performed reaching movements to Targets 2 and 3 so that only their elbow flexors were exposed to the viscous elbow-joint load during training. Figure $8 A$ presents a typical subject's averaged data showing that identical extensor perturbations elicited different hand motion during the adaptation phase and similar motion for flexor perturbations (Fig. $8 B ; F_{(2,26)}=8.74, p<0.001$ ). After training with the viscous elbow load, we found a clear reduction in hand motion for perturbations that extended the elbow (paired $t$ test: baseline vs late adaptation, $p<0.01$ ). In agreement with the results of Experiments 1 and 2, we found that brachio-
A
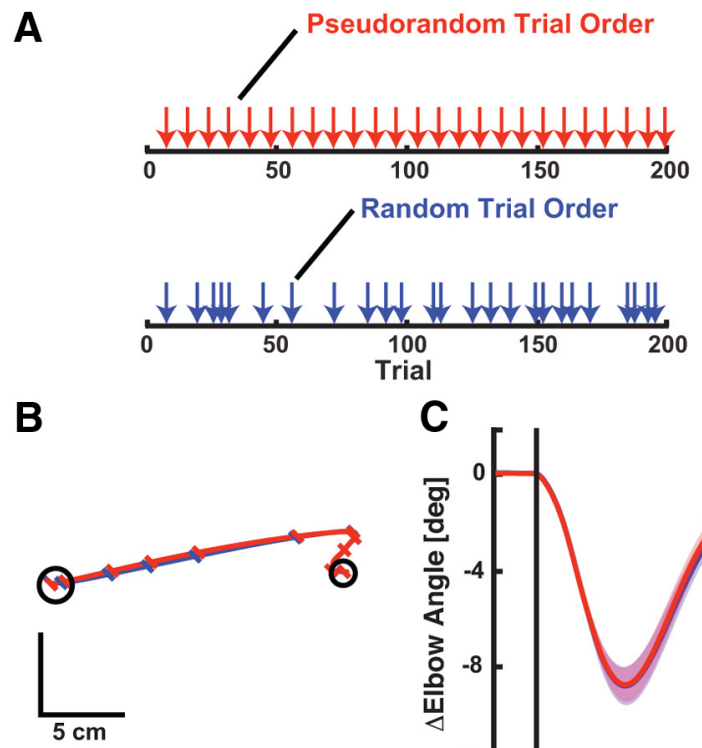

C
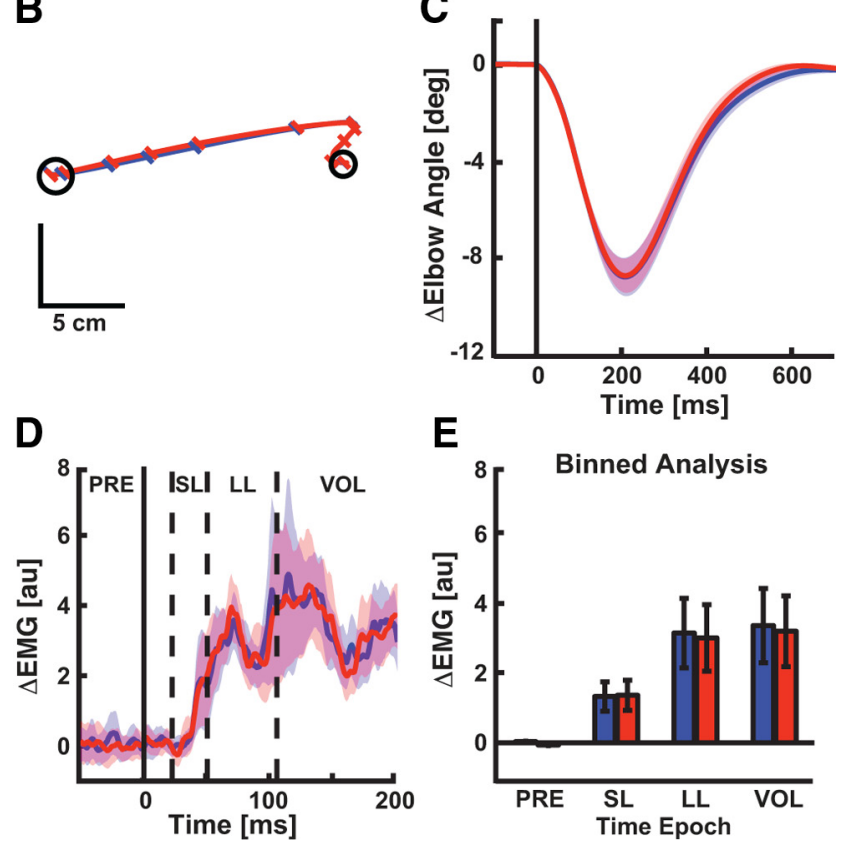

Figure 6. Corrective responses for different perturbation schedules. A, Schematic showing the order of perturbation trials in fixed (unperturbed trials randomized, perturbation trials inserted on every eighth reaching trial; top, red arrows) and random trial blocks (unperturbed and perturbed reaching trials randomized; bottom, blue arrows). $\boldsymbol{B}$, Exemplar data from a single subject showing corrective responses elicited by a mechanical perturbation. Black, red, and blue traces correspond to average responses obtained during the baseline, late adaptation, and washout phases. Diagonal tick marks correspond to the hand position every $100 \mathrm{~ms}$. C, Population-level elbow joint kinematics evoked by mechanical probe trials. Data are aligned to perturbation onset $(t=0 \mathrm{~ms}$; mean $\pm \mathrm{SEM})$. Negative changes in elbow angles represent extension motion caused by the perturbation. $\boldsymbol{D}$, Population averages showing perturbation responses of the brachioradialis muscle (mean \pm SEM). Red and blue traces correspond to brachioradialis responses in the pseudorandom and random trial blocks. $E$, Binned analysis of brachioradialis perturbation responses (mean \pm SEM). ${ }^{*} p<0.05,{ }^{* *} p<0.01,{ }^{* * *} p<0.001$.

radialis activity before perturbation onset (Fig. $8 C ; p=0.178$ ) and the SL spinal response were not significantly altered between phases of the adaptation paradigm $(p=0.151)$, whereas we observed increased brachioradialis responses in the LL $(p<0.01)$ and VOL time periods $(p<0.05)$. We observed corresponding inhibition of the triceps in the LL and VOL time windows for perturbations that extended the elbow (Fig. $8 D ; p<0.05$ ) but did not find any significant differences in PRE triceps activity ( $p=$ $0.926)$ or SL responses $(p=0.997)$. In contrast, hand motion was not significantly altered between phases of the adaptation paradigm when we applied mechanical perturbations that flexed the elbow (Fig. $8 A, B ; p=0.382$ ). This lack of difference in hand motion was not associated with any significant modulation of triceps responses (Fig. 8F; PRE, $p=0.237$; SL, $p=0.690$; LL, $p=$ 0.173 ; VOL, $p=0.382$ ) or brachioradialis responses (Fig. $8 E$; PRE, $p=0.178$; SL, $p=0.151 ; \mathrm{LL}, p=0.956$; VOL,$p=0.199)$. 
A

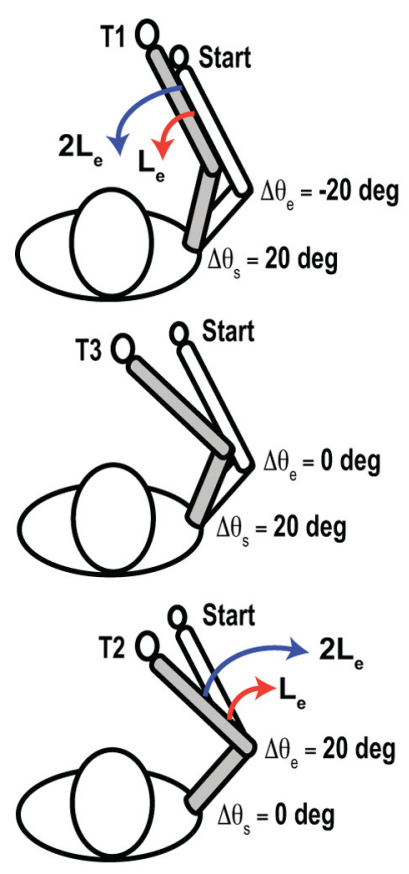

B

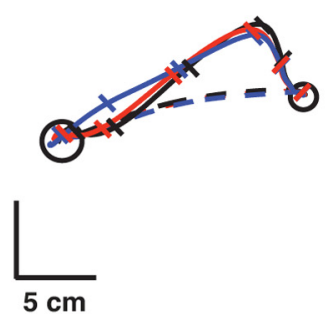

D

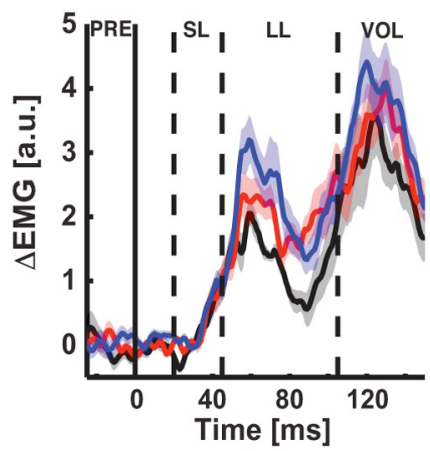

C

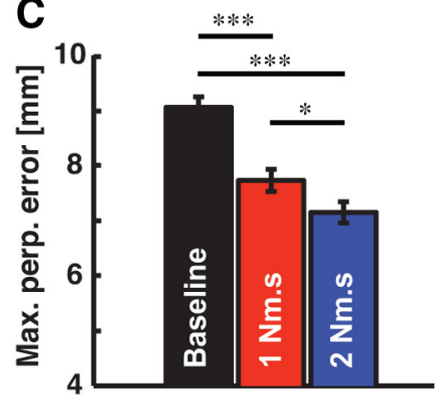

E

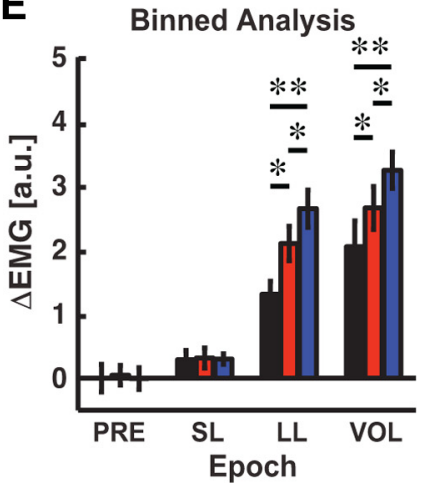

Figure 7. LL responses express knowledge of the viscosity of novel elbow-joint loads. A, Experimental apparatus and target configuration. Red (1 Nm·s/rad) and blue (2 Nm·s/rad) arrows represent the viscous elbow load in the adaptation block. $\boldsymbol{B}$, Exemplar data showing corrective responses across the paradigm. Black, red, and blue traces correspond to unloaded reaching, 1 $\mathrm{Nm} \cdot \mathrm{s} / \mathrm{rad}$ viscous elbow load, and $2 \mathrm{Nm} \cdot \mathrm{s} / \mathrm{rad}$ viscous elbow load. Dashed lines are the average unperturbed reaching movements in each phase of the experiment; solid lines are the average movement in perturbation trials. Diagonal tick marks correspond to the hand position every $100 \mathrm{~ms}$. C, Summary plot showing perturbation-evoked hand motion in each phase of the adaptation paradigm (mean \pm SEM). $\boldsymbol{D}$, Mean perturbation-evoked activity of the brachioradialis muscle $(N=20)$. The dashed lines demarcate the binned epochs used to characterize muscle stretch responses. Horizontal axis is the time relative to perturbation onset (solid vertical line; $t=0 \mathrm{~ms}$ ). The shaded region indicates the $S E M$ with the same color scheme as in $\boldsymbol{B}$. $\boldsymbol{E}$, Binned analysis of muscle stretch responses (mean \pm SEM). Color scheme is the same as in $B .{ }^{*} p<0.05,{ }^{* *} p<0.01,{ }^{* * *} p<0.001$.

A
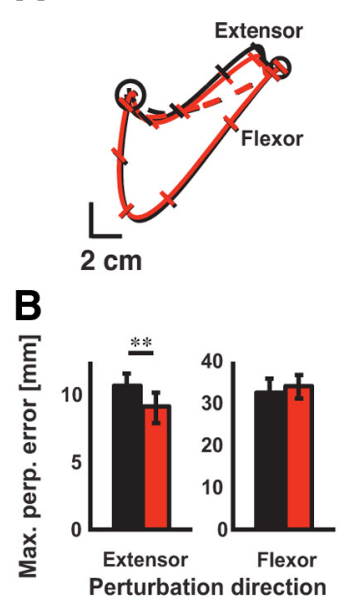

C

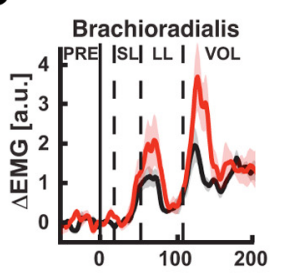

D

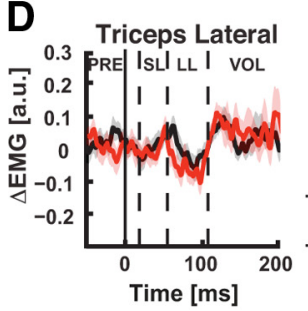

Extensor Perturbations
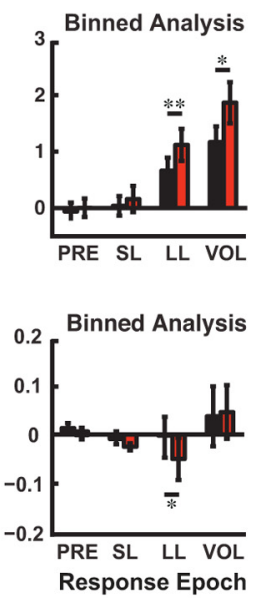

E

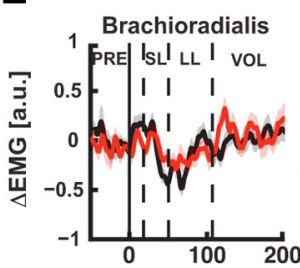

Flexor Perturbations

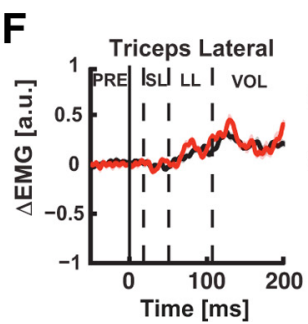

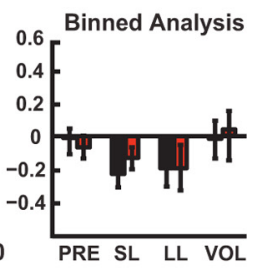

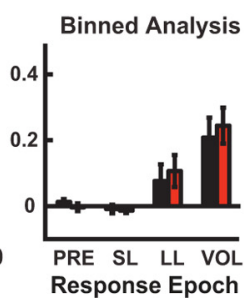

Figure 8. Adaptation of $L L$ responses is sensitive to the direction of the training load. $A$, Representative data from a single subject showing corrective responses across the training paradigm with the brachioradialis muscle preloaded. Black trace corresponds to trajectories during unloaded reaching (baseline); red traces are trajectories from the adaptation phase (viscous elbow load). Solid lines correspond to probe trials ( $\pm 2 \mathrm{Nm}$ step-torque perturbation) and the dashed lines represent unperturbed trajectories. $\boldsymbol{B}$, Summary plot showing maximum perpendicular hand motion (mean \pm SEM) caused by perturbations that extended (left) or flexed (right) the elbow. C, Brachioradialis stretch responses evoked by elbow extensor perturbations. Left panel: Mean perturbation-evoked activity of the brachioradialis muscle for mechanical perturbations that extended the elbow. Vertical dashed lines demarcate the time epochs used to characterize muscle stretch responses. Horizontal axis is the time relative to perturbation onset ( $t=0 \mathrm{~ms}$; solid vertical line). Shaded regions indicate the SEM with black and red shading corresponding to brachioradialis activity in the baseline and adaptation phases, respectively. Right, Binned analysis of brachioradialis stretch responses for perturbations that extended the elbow. $\boldsymbol{D}$, Triceps lateral stretch responses evoked by elbow extensor perturbations. Left, Mean perturbation-evoked activity of the triceps lateral muscle for extensor perturbations. Data are plotted in the same format as in C, Right, Binned analysis of triceps lateral stretch responses for perturbations that extended the elbow. $\boldsymbol{E}$, Brachioradialis stretch responses evoked by elbow flexor perturbations. Left, Mean perturbation-evoked activity of the brachioradialis muscle for perturbations that flexed the elbow. $\boldsymbol{F}$, Triceps lateral stretch responses evoked by perturbations that flexed the elbow. Left, Mean perturbation-evoked activity of the triceps lateral muscle. Right, Binned analysis of triceps lateral responses. Data are plotted in the same format as panel $C .{ }^{*} p<0.05,{ }^{* *} p<0.01,{ }^{* * *} p<0.001$. 


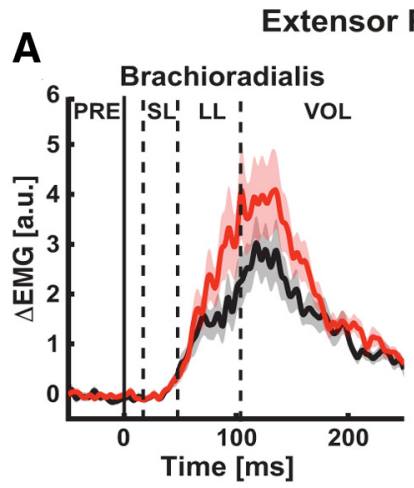

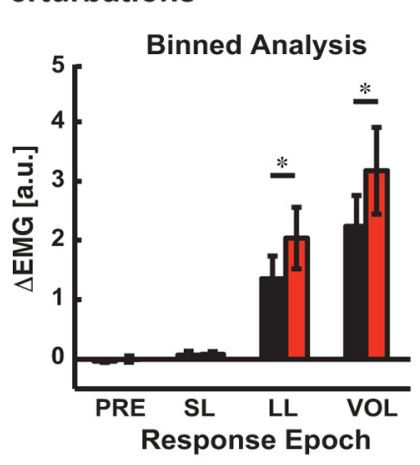
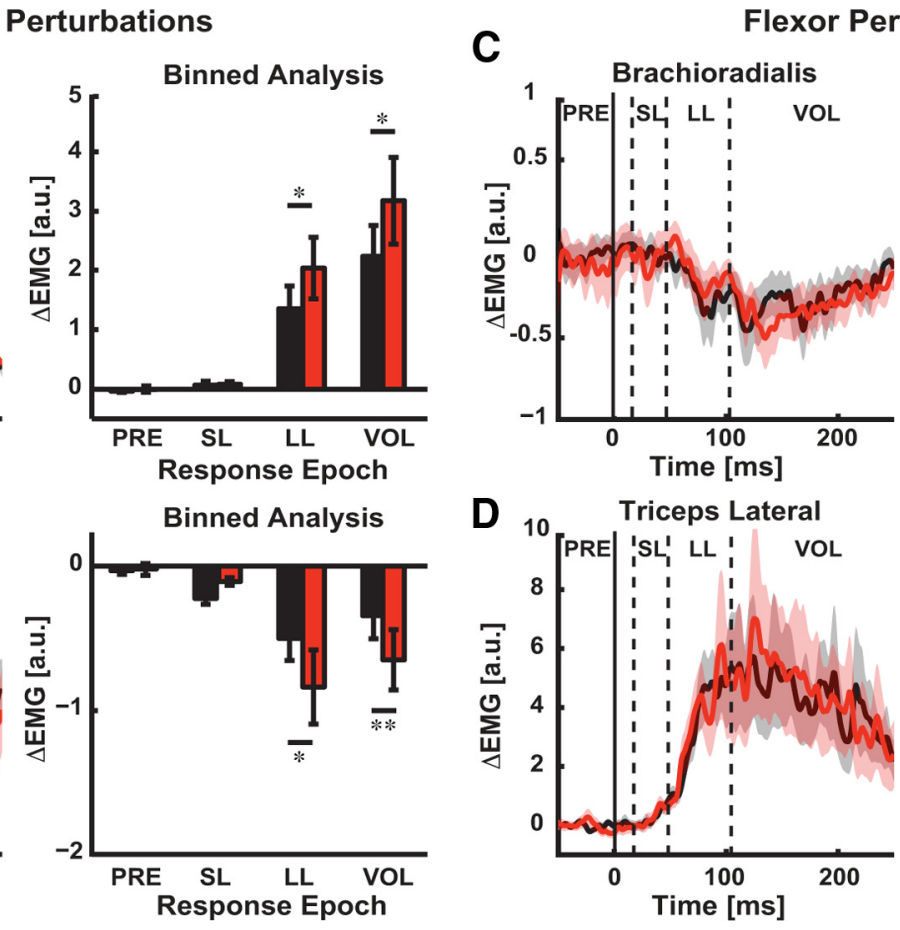

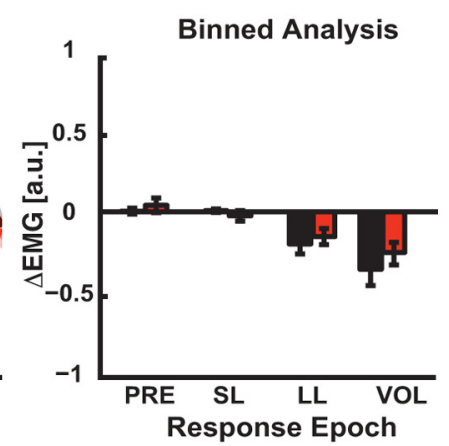

Binned Analysis

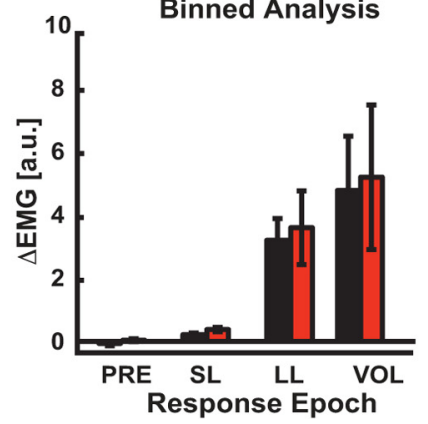

Figure 9. LL responses with the adapted muscle preinhibited are sensitive to the direction of the training load. $\boldsymbol{A}$, Brachioradialis stretch responses evoked by elbow extensor perturbations. Left, Mean perturbation-evoked activity of the preinhibited brachioradialis muscle for mechanical perturbations that extended the elbow. Vertical dashed lines demarcate the time epochs used to characterize muscle feedback responses. Horizontal axis is the time relative to perturbation onset ( $t=0 \mathrm{~ms}$; solid vertical line). Shaded regions indicate the SEM with black and red shading corresponding to brachioradialis activity in the baseline and adaptation phases, respectively. Right, Binned analysis of brachioradialis stretch responses for perturbations that extended the elbow. $\boldsymbol{B}$, Stretch responses for the preloaded triceps lateral muscle evoked by elbow extensor perturbations. Left, Mean perturbation-evoked activity of the triceps lateral muscle for extensor perturbations. Data are plotted in the same format and color scheme as in $\boldsymbol{A}$. Right, Binned analysis of triceps lateral stretch responses for perturbations that extended the elbow. $\boldsymbol{C}$, Brachioradialis stretch responses evoked by elbow flexor perturbations. Left, Mean perturbation-evoked activity of the brachioradialis muscle for perturbations that flexed the elbow. $\boldsymbol{D}$, Triceps lateral stretch responses evoked by perturbations that flexed the elbow. Left, Mean perturbation-evoked activity of the triceps lateral muscle. Right, Binned analysis of triceps lateral responses. Data are plotted in the same format and color scheme as panel $\boldsymbol{A}$. ${ }^{*} p<0.05,{ }^{* *} p<0.01,{ }^{* * *} p<0.001$.

We included an additional condition where we preloaded the triceps with a flexor background load to ensure the lack of difference in these responses was not caused by preinhibition of the triceps. Importantly, we observed adapted brachioradialis stretch responses (Fig. 9A; PRE, $p=0.204$; SL, $p=0.584$; LL, $p<0.05$; VOL, $p<0.05)$ and corresponding inhibition of the triceps responses (Fig. 9B, LL, $p<0.05$; VOL, $p<0.01$ ) when the triceps was preloaded with a flexor background load. However, we still did not observe any significant modulation of triceps stretch responses (Fig. 9D; PRE, $p=0.271$; SL, $p=0.215$; LL, $p=0.234$, VOL, $p=0.214$ ) or brachioradialis responses (Fig. $9 C$; PRE, $p=$ 0.602 ; SL, $p=0.487$; LL, $p=0.245$; VOL, $p=0.173$ ) for perturbations that flexed the elbow. In summary, we found that adaptation was sensitive to the direction of the training load, leading to altered stretch responses in the agonist/antagonist muscle pair when we stretched the muscle that countered the training load with a perturbation.

\section{Discussion}

We investigated changes in feedback responses during the adaptation of reaching movements to a velocity-dependent elbow load. The design of the current study modified reaching behavior at training targets that required elbow motion but did not produce adaptation at a target that required only shoulder motion. This probe target allowed us to measure feedback adaptation independently from changes in voluntary behavior or muscle coactivation. By probing feedback responses with identical elbow perturbations, we demonstrated that the motor system compen- sates for changes in arm dynamics in as little as $\sim 65 \mathrm{~ms}$. In two additional experiments, we modified properties of the viscous elbow load to examine whether feedback responses update based on changes in the task demand. We found that adapted LL responses were modulated by the strength and direction of the training load and were correlated to the adaptation of reaching movements.

When we learn new motor skills, the voluntary motor system learns to approximate the mapping between joint torques and motion (Gandolfo et al., 1996; Conditt et al., 1997). This process enables learning to generalize to untrained regions of the workspace (Goodbody and Wolpert, 1998; Shadmehr and Moussavi, 2000; Malfait et al., 2002, 2005; Joiner et al., 2011). We capitalized on this property and characterized LL responses that compensate for novel elbow-joint loads. This adaptation was concealed during unperturbed reaching movements to a probe target that required only shoulder motion, but was expressed following a mechanical perturbation that displaced the elbow joint during the reach.

There has been increasing interest in studying the properties of muscle stretch responses because they provide a window into voluntary control processes during the earliest stages of cortical feedback processing (Scott, 2012). A number of studies have highlighted LL responses that are sensitive to limb dynamics (Kurtzer et al., 2009), sensorimotor decisions (Selen et al., 2012), and the spatial location and shape of the behavioral goal (Pruszynski et al., 2008; Nashed et al., 2012). The current work 
extends beyond these previous studies on feedback responses by providing evidence that sophisticated corrective responses are linked to the adaptation of voluntary control. In our task, corrective elbow responses were required to reach the target during probe trials, and we observed robust increases in stretch responses while subjects trained with the viscous elbow load. Our results compliment previous work highlighting feedback corrections that are altered by training with novel hand forces (Wagner and Smith, 2008; Kimura and Gomi, 2009; Yousif and Diedrichsen, 2012). Adaptive stretch responses have even been found during the preparatory period before reach onset (Ahmadi-Pajouh et al., 2012), suggesting that reach adaptation may have the capability to alter corrective responses engaged for postural control. This transfer of learning may reflect the partial overlap in neural control across reaching and posture tasks (Kurtzer et al., 2005).

A number of studies have shown that the biomechanical properties of the limb can be modified to control initial perturbation responses (Franklin et al., 2008; Perreault et al., 2008; Selen et al., 2009; Kadiallah et al., 2012). Adaptation to stable forces (i.e., viscous loads) similar to the novel loads used in this study appear to involve a rapid increase followed by slow reduction in muscle coactivation (Franklin et al., 2008) with simultaneous modification of reciprocal muscle activation profiles (i.e., movement agonists/antagonists). This adaptation pattern allows learning to generalize across movement directions and produces curved after-effect deviations (Osu et al., 2003). Consistent with these findings, we found altered muscle coactivation and after-effect deviations at our training targets, but importantly, we did not observe behavioral changes or altered muscle activity that would confound our ability to measure adapted feedback responses at the probe target.

Our paradigm enabled us to demonstrate that adaptation produces flexible LL responses that scale with the magnitude of novel loads applied to the arm. By dissociating feedback responses from changes in background activity, we were able to explore several other key properties of adapted feedback control. Most notably, we observed upregulation of LL responses simultaneous with the adaptation of voluntary reaching kinematics. LL responses were maximal at the asymptote of learning and decayed rapidly during the de-adaptation of reaching movements. Adaptation profiles have been studied extensively for voluntary reaching movements (Scheidt et al., 2000; Smith et al., 2006) but we have provided the first clear evidence linking systematic changes in LL responses to reach adaptation.

We investigated this link by applying perturbations in fixed order (every eighth trial in Experiments 1 and 2). One potential concern is that subjects may increase background muscle activity to counter the load (i.e., preflex; Loeb et al., 1999) or amplify SL responses to minimize motion caused by the perturbation (Matthews, 1986; Pruszynski et al., 2009). The earliest adapted responses in our experiments were in the LL time period, with no changes in background activity or SL responses. Importantly, we replicated these findings in Experiment 3 when the direction and order of perturbations were random, and showed in a separate control experiment that the order of perturbation trials did not affect stretch responses. This provides further evidence in support of adaptive feedback responses in our task.

Another notable result was the asymmetric adaptation of feedback responses observed when we applied the load in a single direction during training. We found that perturbations exciting the elbow flexors (both with the flexors and extensors preloaded) elicited increases in brachioradialis responses and corresponding inhibition of triceps activity, but this adaptation was not observed when the triceps was stretched by a flexor perturbation. We think this result may be related to active inhibition of the antagonist due to the neural circuitry engaged by mechanical perturbations (Manning et al., 2013). It has been widely observed that corticomotoneuronal cells tend to have reciprocal connections that excite agonist muscles and inhibit antagonist muscles (Conrad et al., 1975; Evarts and Tanji, 1976; Lemon and Porter, 1976; Cheney and Fetz, 1985). Thus, adaptive increases in the stretch response from transcortical feedback to the elbow flexor muscles should also produce greater inhibition of the elbow extensor muscles.

Another striking result was that, across subjects, changes in feedback sensitivity correlated with performance in the learned motor task. This result further highlights the relationship between feedback responses and the extent of motor adaptation, and excludes the possibility that external loads produce nonspecific increases in feedback responses. Although our results are consistent with the observation that corticospinal excitability is modulated by the extent of motor adaptation (Ostry et al., 2010; Vahdat et al., 2011; Orban de Xivry et al., 2013), to our knowledge, this link had not been noted for muscle stretch responses.

The relationship between adapted reaching behavior and feedback control is consistent with work showing the voluntary motor system accounts for the physical properties of the limb and that this capability is expressed in the activity of primary motor cortex neurons (Scott et al., 2001; Pruszynski et al., 2011). Primary motor cortex plays an important role in motor skill acquisition, evidenced by neural discharge patterns that adapt after training with novel forces (Gandolfo et al., 2000; Sanes and Donoghue, 2000; Li et al., 2001) and the observation that transcranial magnetic stimulation applied to M1 in humans alters adapted reaching behavior (Kimura et al., 2006). Although feedback processing likely involves many cortical and subcortical structures (Desmedt, 1978; Scott, 2004, 2012) including somatosensory areas (Fromm and Evarts, 1977), transcortical pathways through primary motor cortex play a key role in the generation of LL responses (Evarts, 1973; Evarts and Tanji, 1976; Pruszynski et al., 2011). Together, research has shown that M1 is involved in the acquisition and online control of novel motor skills, and a reasonable hypothesis is the adapted feedback responses outlined here may involve modified primary motor cortex processing.

An alternative explanation is that the adaptation of forward models leads to corresponding changes in LL stretch responses (Wolpert and Kawato, 1998; Shadmehr et al., 2010). This hypothesis is consistent with evidence that forward models can alter feedback responses in the presence of arbitrary environmental forces (Mehta and Schaal, 2002; Wagner and Smith, 2008; Crevecoeur and Scott, 2013). The cerebellum may be involved in feedback corrections as it is richly interconnected with M1 (Evarts and Thach, 1969; Middleton and Strick, 2001), is involved in the modulation of LL responses (Kurtzer et al., 2013) and motor skill learning (Miall et al., 1993, 2007; Doya, 1999), and responds to external perturbations during the LL epoch (Strick, 1979). Further research is needed to investigate whether adapted feedback responses arise from local pathways in M1 or other areas along transcortical pathways.

We have provided evidence that feedback control during reaching compensates for novel loads applied to the arm. We suggest this adaptation is related to overlap in the neural substrates engaged for voluntary behavior and online feedback responses. If true, we expect rapid feedback responses to express other key attributes of voluntary control including spatial generalization functions (Sing et al., 2009), structural learning (Kobak 
and Mehring, 2012), and the ability to adapt feedback responses by simply observing others learning new motor skills (Mattar and Gribble, 2005).

\section{References}

Ahmadi-Pajouh MA, Towhidkhah F, Shadmehr R (2012) Preparing to reach: selecting an adaptive long-latency feedback controller. J Neurosci 32:9537-9545. CrossRef Medline

Brown IE, Loeb GE (2000) A reductionist approach to creating and using neuromusculoskeletal models. In: Biomechanics and neural control of posture and movement (Winters JM, Crago PE, eds), pp 148-163. New York: Springer.

Burdet E, Osu R, Franklin DW, Milner TE, Kawato M (2001) The central nervous system stabilizes unstable dynamics by learning optimal impedance. Nature 414:446-449. CrossRef Medline

Cheney PD, Fetz EE (1985) Comparable patterns of muscle facilitation evoked by individual corticomotoneuronal (CM) cells and by single intracortical microstimuli in primates: evidence for functional groups of CM cells. J Neurophysiol 53:786-804. Medline

Conditt MA, Gandolfo F, Mussa-Ivaldi FA (1997) The motor system does not learn the dynamics of the arm by rote memorization of past experience. J Neurophysiol 78:554-560. Medline

Conrad B, Meyer-Lohmann J, Matsunami K, Brooks VB (1975) Precentral unit activity following torque pulse injections into elbow movements. Brain Res 94:219-236. CrossRef Medline

Crevecoeur F, Scott SH (2013) Priors engaged in LL responses to mechanical perturbations suggest a rapid update in state estimation. PLoS Comput Biol 9:e1003177. CrossRef Medline

Darainy M, Ostry DJ (2008) Muscle cocontraction following dynamics learning. Exp Brain Res 190:153-163. CrossRef Medline

Desmedt J (1978) Cerebral motor control in man: long loop mechanisms. Basel: Karger.

Diedrichsen J, Shadmehr R, Ivry RB (2010) The coordination of movement: optimal feedback control and beyond. Trends Cogn Sci 14:31-39. CrossRef Medline

Doya K (1999) What are the computations of the cerebellum, the basal ganglia and the cerebral cortex? Neural Netw 12:961-974. CrossRef Medline

Evarts EV (1973) Motor cortex reflexes associated with learned movement. Science 179:501-503. CrossRef Medline

Evarts EV, Tanji J (1976) Reflex and intended responses in motor cortex pyramidal tract neurons of monkey. J Neurophysiol 39:1069-1080. Medline

Evarts EV, Thach WT (1969) Motor mechanisms of the CNS: cerebrocerebellar interrelations. Annu Rev Physiol 31:451-498. CrossRef Medline

Franklin DW, Liaw G, Milner TE, Osu R, Burdet E, Kawato M (2007) Endpoint stiffness of the arm is directionally tuned to instability in the environment. J Neurosci 27:7705-7716. CrossRef Medline

Franklin DW, Burdet E, Tee KP, Osu R, Chew CM, Milner TE, Kawato M (2008) CNS learns stable, accurate, and efficient movements using a simple algorithm. J Neurosci 28:11165-11173. CrossRef Medline

Franklin S, Wolpert DM, Franklin DW (2012) Visuomotor feedback gains upregulate during the learning of novel dynamics. J Neurophysiol 108: 467-478. CrossRef Medline

Fromm C, Evarts EV (1977) Relation of motor cortex neurons to precisely controlled and ballistic movements. Neurosci Lett 5:259-265. CrossRef Medline

Gandolfo F, Mussa-Ivaldi FA, Bizzi E (1996) Motor learning by field approximation. Proc Natl Acad Sci U S A 93:3843-3846. CrossRef Medline

Gandolfo F, Li C, Benda BJ, Schioppa CP, Bizzi E (2000) Cortical correlates of learning in monkeys adapting to a new dynamical environment. Proc Natl Acad Sci U S A 97:2259-2263. CrossRef Medline

Goodbody SJ, Wolpert DM (1998) Temporal and amplitude generalization in motor learning. J Neurophysiol 79:1825-1838. Medline

Gottlieb GL, Chen CH, Corcos DM (1995) Relations between joint torque, motion, and electromyographic patterns at the human elbow. Exp Brain Res 103:164-167. Medline

Hoffman DS, Strick PL (1993) Step-tracking movements of the wrist: III. Influence of changes in load on patterns of muscle activity. J Neurosci 13:5212-5227. Medline

Holm S (1979) A simple sequentially rejective multiple test procedure. Scandinavian J Stat 6:65-70.

Joiner WM, Ajayi O, Sing GC, Smith MA (2011) Linear hypergeneralization of learned dynamics across movement speeds reveals anisotropic, gainencoding primitives for motor adaptation. J Neurophysiol 105:45-59. CrossRef Medline

Kadiallah A, Franklin DW, Burdet E (2012) Generalization in adaptation to stable and unstable dynamics. PLoS ONE 7:e45075. CrossRef Medline

Kimura T, Gomi H (2009) Temporal development of anticipatory reflex modulation to dynamical interactions during arm movement. J Neurophysiol 102:2220-2231. CrossRef Medline

Kimura T, Haggard P, Gomi H (2006) Transcranial magnetic stimulation over sensorimotor cortex disrupts anticipatory reflex gain modulation for skilled action. J Neurosci 26:9272-9281. CrossRef Medline

Kobak D, Mehring C (2012) Adaptation paths to novel motor tasks are shaped by prior structure learning. J Neurosci 32:9898-9908. CrossRef Medline

Kurtzer IL, Pruszynski JA, Scott SH (2008) Long-latency reflexes of the human arm reflect an internal model of limb dynamics. Curr Biol 18:449453. CrossRef Medline

Kurtzer IL, Trautman P, Rasquinha RJ, Bhanpuri NH, Scott SH, Bastian AJ (2013) Cerebellar damage diminishes long-latency responses to multijoint perturbations. J Neurophysiol 109:2228-2241. CrossRef Medline

Kurtzer I, Herter TM, Scott SH (2005) Random change in cortical load representation suggests distinct control of posture and movement. Nat Neurosci 8:498-504. CrossRef Medline

Kurtzer I, Pruszynski JA, Scott SH (2009) Long-latency responses during reaching account for the mechanical interaction between the shoulder and elbow joints. J Neurophysiol 102:3004-3015. CrossRef Medline

Lemon RN, Porter R (1976) Afferent input to movement-related precentral neurones in conscious monkeys. Proc R Soc Lond B 194:313-339. CrossRef Medline

Li CS, Padoa-Schioppa C, Bizzi E (2001) Neuronal correlates of motor performance and motor learning in the primary motor cortex of monkeys adapting to an external force field. Neuron 30:593-607. CrossRef Medline

Loeb GE, Brown IE, Cheng EJ (1999) A hierarchical foundation for models of sensorimotor control. Exp Brain Res 126:1-18. CrossRef Medline

Malfait N, Shiller DM, Ostry DJ (2002) Transfer of motor learning across arm configurations. J Neurosci 22:9656-9660. Medline

Malfait N, Gribble PL, Ostry DJ (2005) Generalization of motor learning based on multiple field exposures and local adaptation. J Neurophysiol 93:3327-3338. CrossRef Medline

Manning CD, Tolhurst SA, Bawa P (2012) Proprioceptive reaction times and long-latency reflexes in humans. Exp Brain Res 221:155-166. CrossRef Medline

Manning CD, McDonald PL, Murnaghan CD, Bawa P (2013) Reciprocal inhibition versus unloading response during stretch reflex in humans. Exp Brain Res 226:33-43. CrossRef Medline

Mattar AA, Gribble PL (2005) Motor learning by observing. Neuron 46: 153-160. CrossRef Medline

Mattar AA, Ostry DJ (2007) Modifiability of generalization in dynamics learning. J Neurophysiol 98:3321-3329. CrossRef Medline

Matthews PB (1986) Observations on the automatic compensation of reflex gain on varying the pre-existing level of motor discharge in man. J Physiol 374:73-90. Medline

Mehta B, Schaal S (2002) Forward models in visuomotor control. J Neurophysiol 88:942-953. Medline

Miall RC, Weir DJ, Wolpert DM, Stein JF (1993) Is the cerebellum a smith predictor? J Mot Behav 25:203-216. CrossRef Medline

Miall RC, Christensen LO, Cain O, Stanley J (2007) Disruption of state estimation in the human lateral cerebellum. PLoS Biol 5:e316. CrossRef Medline

Middleton FA, Strick PL (2001) Cerebellar projections to the prefrontal cortex of the primate. J Neurosci 21:700-712. Medline

Milner TE, Franklin DW (2005) Impedance control and internal model use during the initial stage of adaptation to novel dynamics in humans. J Physiol 567:651-664. CrossRef Medline

Nashed JY, Crevecoeur F, Scott SH (2012) Influence of the behavioral goal and environmental obstacles on rapid feedback responses. J Neurophysiol 108:999-1009. CrossRef Medline

Ostry DJ, Darainy M, Mattar AA, Wong J, Gribble PL (2010) Somatosensory plasticity and motor learning. J Neurosci 30:5384-5393. CrossRef Medline

Osu R, Burdet E, Franklin DW, Milner TE, Kawato M (2003) Different 
mechanisms involved in adaptation to stable and unstable dynamics. J Neurophysiol 90:3255-3269. CrossRef Medline

Perreault EJ, Chen K, Trumbower RD, Lewis G (2008) Interactions with compliant loads alter stretch reflex gains but not intermuscular coordination. J Neurophysiol 99:2101-2113. CrossRef Medline

Pfann KD, Hoffman DS, Gottlieb GL, Strick PL, Corcos DM (1998) Common principles underlying the control of rapid, single degree-of-freedom movements at different joints. Exp Brain Res 118:35-51. CrossRef Medline

Pruszynski JA, Kurtzer I, Scott SH (2008) Rapid motor responses are appropriately tuned to the metrics of a visuospatial task. J Neurophysiol 100: 224-238. CrossRef Medline

Pruszynski JA, Kurtzer I, Lillicrap TP, Scott SH (2009) Temporal evolution of "automatic gain-scaling." J Neurophysiol 102:992-1003. CrossRef Medline

Pruszynski JA, Kurtzer I, Nashed JY, Omrani M, Brouwer B, Scott SH (2011) Primary motor cortex underlies multi-joint integration for fast feedback control. Nature 478:387-390. CrossRef Medline

Sanes JN, Donoghue JP (2000) Plasticity and primary motor cortex. Annu Rev Neurosci 23:393-415. CrossRef Medline

Scheidt RA, Reinkensmeyer DJ, Conditt MA, Rymer WZ, Mussa-Ivaldi FA (2000) Persistence of motor adaptation during constrained, multi-joint, arm movements. J Neurophysiol 84:853-862. Medline

Scott SH (1999) Apparatus for measuring and perturbing shoulder and elbow joint positions and torques during reaching. J Neurosci Methods 89:119-127. CrossRef Medline

Scott SH (2004) Optimal feedback control and the neural basis of volitional motor control. Nat Rev Neurosci 5:532-546. CrossRef Medline

Scott SH (2012) The computational and neural basis of voluntary motor control and planning. Trends Cogn Sci 16:541-549. CrossRef Medline

Scott SH, Gribble PL, Graham KM, Cabel DW (2001) Dissociation between hand motion and population vectors from neural activity in motor cortex. Nature 413:161-165. CrossRef Medline

Selen LP, Franklin DW, Wolpert DM (2009) Impedance control reduces instability that arises from motor noise. J Neurosci 29:12606-12616. CrossRef Medline

Selen LP, Shadlen MN, Wolpert DM (2012) Deliberation in the motor system: reflex gains track evolving evidence leading to a decision. J Neurosci 32:2276-2286. CrossRef Medline

Shadmehr R, Moussavi ZM (2000) Spatial generalization from learning dynamics of reaching movements. J Neurosci 20:7807-7815. Medline
Shadmehr R, Mussa-Ivaldi FA (1994) Adaptive representation of dynamics during learning of a motor task. J Neurosci 14:3208-3224. Medline

Shadmehr R, Smith MA, Krakauer JW (2010) Error correction, sensory prediction, and adaptation in motor control. Annu Rev Neurosci 33:89-108. CrossRef Medline

Sing GC, Joiner WM, Nanayakkara T, Brayanov JB, Smith MA (2009) Primitives for motor adaptation reflect correlated neural tuning to position and velocity. Neuron 64:575-589. CrossRef Medline

Singh K, Scott SH (2003) A motor learning strategy reflects neural circuitry for limb control. Nat Neurosci 6:399-403. CrossRef Medline

Smith MA, Ghazizadeh A, Shadmehr R (2006) Interacting adaptive processes with different timescales underlie short-term motor learning. PLoS Biol 4:e179. CrossRef Medline

Soechting JF, Lacquaniti F (1988) Quantitative evaluation of the electromyographic responses to multidirectional load perturbations of the human arm. J Neurophysiol 59:1296-1313. Medline

Strick PL (1979) Cerebellar involvement in volitional muscle responses to load changes. In: Cerebal motor control in man: Long loop mechanisms, Ed 4. New York: Karger.

Thoroughman KA, Shadmehr R (1999) Electromyographic correlates of learning an internal model of reaching movements. J Neurosci 19:85738588. Medline

Todorov E, Jordan MI (2002) Optimal feedback control as a theory of motor coordination. Nat Neurosci 5:1226-1235. CrossRef Medline

Vahdat S, Darainy M, Milner TE, Ostry DJ (2011) Functionally specific changes in resting-state sensorimotor networks after motor learning. J Neurosci 31:16907-16915. CrossRef Medline

Wagner MJ, Smith MA (2008) Shared internal models for feedforward and feedback control. J Neurosci 28:10663-10673. CrossRef Medline

Wolpaw JR (1985) Adaptive plasticity in the spinal stretch reflex: an accessible substrate of memory? Cell Mol Neurobiol 5:147-165. CrossRef Medline

Wolpert DM, Kawato M (1998) Multiple paired forward and inverse models for motor control. Neural Netw 11:1317-1329. CrossRef Medline

Wolpert DM, Diedrichsen J, Flanagan JR (2011) Principles of sensorimotor learning. Nat Rev Neurosci 12:739-751. CrossRef Medline

Orban de Xivry JJ, Ahmadi-Pajouh MA, Harran MD, Salimpour Y, Shadmehr R (2013) Changes in corticospinal excitability during reach adaptation in force fields. J Neurophysiol 109:124-136. CrossRef Medline

Yousif N, Diedrichsen J (2012) Structural learning in feedforward and feedback control. J Neurophysiol 108:2373-2382. CrossRef Medline 